\title{
Application of Embedded Technology in Smart Home
}

\author{
Xiuguo Zhang \\ School of Electronics and Information Engineering of Zhu Hai City Polytechnic, Zhuhai, Guangdong, \\ 519090, China
}

\begin{abstract}
The history and current status of smart home are described and the basic idea of intelligent control is introduced .And the application of embedded system in intelligent control system is also discussed. Using embedded system, various network information, multiplex automatic control function, as well as energy saving and environmental protection can be integrated into one platform of home intelligent information administration and automatic monitoring. As a result, efficient, comfortable, safe and protected living environment can be achieved.
\end{abstract}

KEYWORD: Smart Home; Intelligent Control; Embedded System

\section{INTRODUCTION}

In early 1980s, in the field of interior design appeared the idea of smart home, initially included in the residential interior monitoring and management functions. With the development of Internet, the connotation of "smart home" also immediately new expansion, and gradually formed a residential as a platform, both architecture, network communication, information appliance and equipment automation, set system, structure, service and management is one of the efficient, comfortable, safe and convenient, environmentally friendly living environment. Smart home is refers to the family in a variety of information related to communications equipment, household appliances, home security device, through the family bus technology (Hbus) connected to a family intelligent platform, centralized or remote monitoring, control and management of family affairs, and maintain the harmony and coordination of these facilities family and life demand and residential environment

China's smart home development began at the end of the last century, although it is just started, but after a few years of development, regardless of professional manufacturers or agents, the number of engineering companies are greatly increased. Smart home products are becoming a trend of home products continue to flow into the city Field, although the shape is different, but its content can not be separated from the intelligent electrical control and security management. Now China's real estate industry has developed rapidly, so China's smart home market has great potential, as its downstream industry, smart home market prospects are very optimistic.

\section{THE WORKING PRINCIPLE OF SMART HOME SYSTEM}

Community management center is a smart home system connected to the outside world, in the establishment of community management information system based on Web server, when an accident family and related sensors will alarm information is automatically through the family bus system sent to the network terminal, the terminal through an interface can alarm information directly to the user's mobile phone, but also through the district network alarm information is sent to the management center of the area. The user can directly browse the current status of the home device through the Internet browser, and can directly control the household equipment through the web. Home network terminal can be through the telephone interface directly connected to PSTN, when users dial the home phone control of home appliances, control information through the browser to the web server, and then the community management center computer control information is forwarded to the corresponding network terminal, terminal control information forwarded directly to the associated control equipment, completes the control work. After the completion of the control, the network terminal and the results of information feedback back to the district management center computer, community management center will be 
written to the database, and feedback to the user to send control requests. Control household appliances through telephone set with a password function, only after the password is more successful to enter the control module, so that the operation is more secure.

\section{SOLUTION OF HOME INTELLIGENT CONTROL SYSTEM}

Intelligent home control system has three solutions, which is based on PC, microcontroller and embedded systems of three kinds of intelligent home control system solutions respectively represent the technical features of the smart home industry in China in different periods. There three solutions: one is Smart home based on PC machine architecture, one is based on single chip architecture system, and one is Smart home based on Embedded System

\section{THE APPLICATION OF EMBEDDED TECHNOLOGY IN THE HOME INTELLIGENT CONTROL SYSTEM}

Embedded system generally refers to non PC system, in accordance with the requirements of history, nature, universality, embedded system should be defined as: "embedded into the object system of the special computer system". "Embedded", "special" and "computer system" are the three basic elements of embedded system. Object system is the embedded system of embedded system. Generally, embedded system is used as the center, to computer technology as the foundation and hardware and software can be cut, it is suitable for in application system and strict specialized computer system to function, reliability, cost, volume, power consumption. The embedded system mainly consists of two parts, hardware and software, which is used to control, monitor or manage other devices. Hardware, including processor, memory, external devices, and IO control port, graphics controller, etc.. The software part includes the operating system software (OS) and the application program which can realize real-time and multi task operation. Sometimes designers combine these two software together. The application controls the operation and behavior of the system, and the operating system controls the interaction between the application program and the hardware. The core of embedded system is embedded microprocessor.

Embedded microprocessor generally has the following 4 characteristics:

(1) Have very strong support ability to multitask, can perform multiple tasks and short interrupt response time.

(2) Having a storage area protection function is very strong. This is because the embedded system software architecture is modular, and in order to avoid errors in interactions between software modules, need to design a storage area protection func- tion is powerful, but also conducive to the diagnostic software.

(3) Scalable processor architecture.

(4) Embedded microprocessors have to be very low power consumption, and rely on battery powered for portable wireless and mobile computing and communication devices in the embedded system is even more so, such as the need for power consumption is only $\mathrm{mW}$ or even $\mathrm{W}$ level.

In addition, when you understand the definition of embedded systems, do not be confused with embedded devices. Embedded equipment refers to the internal embedded system products and equipment, for example, household appliances, instrumentation, industrial robots, mobile phone unit, PDA, embedded MCU Etc.

The birth and development of the embedded technology, promote the coming of the post PC era, embedded system in the field of communication products, household appliances, medical equipment, automobile manufacturing, aerospace and other infinite use of space has made it become to promote the development of the information industry, accelerate the transformation of traditional industries most practical high technology. Embedded technology in the application of home intelligent control system, the system of voice and image processing ability greatly enhanced. According to the real-time operating system customization system can not only maximize the hardware investment, but also to avoid the waste caused by too large for the system. Because the embedded system generally only a core processing chip, so the system structure more clear and simple. The system software uses the hierarchical design, not only has the advantages of convenient maintenance and to upgrade the system, but also greatly improve the utilization rate of the code, shorten the development cycle. In addition, the embedded technology is produced and developed with Internet, so it has more excellent network performance, can increase the network application.

The embedded intelligent home control system can be set up and control the following functions:

(1) Visual intercom. The installation of video intercom system in the hall, library etc.. Visitors must be subject to the consent of the tenants, the household remote control to open the door to enter the unit security door. Unit door host can also be connected through the network and management center host, in the future, visitors enter the signal transmitted to the host at the same time, to facilitate the duty staff to grasp the situation of visitors.

(2) Alarm. Can be divided into anti-theft alarm and alarm, closed-circuit monitoring system and emergency call and alarm etc.. Burglar alarm. The installation of anti-theft probe on the wall or ceiling at the living room, hallway and staircase. The interior used in the windows and doors etc.. Applied to outdoor walls, balcony window, etc., if one can de- 
tect the illegal intrusion. Menci, window magnetic probe mounted on the door and the window closed. Once the doors and windows are opened, they will be detected, and the alarm will be immediately detected. In addition, the use of high-speed cameras or cameras, once the alarm occurs, the scene will automatically take pictures or video.

Disaster prevention and warning. Installation of gas leak probe and temperature sensing and smoke detector in the room. When the flammable gas leakage occurs, it will send an alarm signal. After triggering the alarm, in addition to the community through the network to the security center alarm, but also through the Internet or call the user to set the phone to call the police. At the same time open house exhaust fan to remove harmful gases. When the detection range of temperature or smoke fire detector can detect and alarm (alarm or alarm communication). If there is a fire sprinkler system, automatically spray.

Emergency call and alarm system. In many indoor set emergency alarm button, such as bedroom bedside, study or in the bathroom. When the patient is stolen, sudden illness and other emergencies, the alarm can be directly to the community security center, so that tenants get timely assistance.

(3) Information terminal. Can receive community management center issued a community bulletin, household notification, browse the web and receive mail, SMS, and check the alarm information and tables of information.

(4) Automatic meter reading. Will take electronic collector gas table, ammeter, water meter, heat meter etc. from indoor wiring through the family information access box leads to outdoor acquisition system assembly, connection and residential property management center, in the administration center main unit may at any time by manual or automatic way of transcribing meter readings. The input of local water, electricity and gas prices. You can automatically calculate the cost. And print out the reading and billing situation.

(5) Remote monitoring. When there is a need to take care of the elderly and children, can these people in the installation of cameras where the environment can be observed through the remote network need to take care of the situation. In addition, when the alarm is triggered, can also be through the development of remote monitoring in Internet.

(6) Network home appliances control. Can be used by telephone, SMS, Internet and other remote control of household appliances (such as microwave ovens, rice cooker, water heater, air conditioners, washing machines, etc.). The future of home appliances will have data interface, remote control can be achieved through the data network. The data information socket can be arranged beside the power socket of the household electric appliance which may require remote control of the network.
(7) Music, video and lighting control. Audio and video signals are connected to each need through the distribution of the room, to achieve a VCD (DVD) play, a number of rooms can be watched by television. Install the background sound system and lighting centralized control at home

The system, through the touch screen on the gateway, SMS, telephone, mobile phone socket and Internet remote control of home, and then realize the centralized control of audio, video and lighting of the family.

\section{CONCLUSION}

If the architecture is the solidification of music, then the perfect family intelligent automatic control system is the music the most wonderful notes, called the whole building of soul and the finishing touch of the pen. With the rapid development and popularization of network system, and the mainstream consumer of smart home acceptance improve, smart home will no longer out of reach, it is a step by step quietly entered the lives of every one of us, and change our way of life and life philosophy. Of course, smart home is not isolated, it needs the support of home broadband network, it home appliance, information intelligent tools, such as a variety of factors, according to Cleveland, a consultancy report is expected by 2008, global introduction of family home network will increase to nearly 115 billion. With such a platform, the smart home will usher in a broader space for development.

\section{REFERENCES}

ARASARATNAM I, HAYKIN S. the Embedded Technology in Smart Home. IEEE Trans. On Automatic Control, 2009, 54 (6):1254-1269.

Jack Ganessle. Changes in Embedd Design Methodolody. Embedded System Programming, 2013(5). 